\title{
New European Rules Regarding the Approval of Clinical Trials, the Role of Ethics Committees and the Protection of Subjects
}

\author{
Herman Nys
}

Received: 15 September 2012/ Accepted: 24 September 2012/Published online: 13 October 2012

(C) L. Hirszfeld Institute of Immunology and Experimental Therapy, Wroclaw, Poland 2012

\section{Introduction}

In its Communication of 10th December 2008 on 'Safe, innovative and accessible medicines: a renewed vision for the pharmaceutical sector' ${ }^{1}$ the European Commission announced that an assessment would be made of the clinical trials Directive. In October 2009, the Commission published a Public Consultation Paper regarding the envisaged assessment. ${ }^{2}$ After the consultation procedure, the Commission published on 17th July 2012 a proposal for a Regulation of the European Parliament and of the Council on clinical trials on medicinal products for human use, and repealing Directive 2001/20/EC. ${ }^{3}$ It is not the aim of this contribution to describe the proposed Regulation in its entirety. It is limited on how the proposed Regulation regulates the ethical assessment of clinical trials and the protection of participants in clinical trials compared with the existing rules in the Directive. The next paragraph contains a short overview of the clinical trials Directive. This is followed by a brief description of the outcome of the consultation procedure in as much as it is pertinent to this contribution. The rules in the proposed Regulation governing the ethical assessment of clinical trials on the one hand and the protection of subjects participating in such trials on the other hand are analysed in the next two paragraphs. Finally, this contribution closes with a brief discussion of the merits and weaknesses of the proposed Regulation.

H. Nys is a Member of the European Group on Ethics of Science and New Technologies to the European Commission (2011-2016).

H. Nys $(\bowtie)$

KU Leuven, Leuven, Belgium

e-mail: Herman.Nys@med.kuleuven.be

\section{Brief Overview of the Clinical Trials Directive}

The conduct of clinical trials on medicinal products for human use is actually regulated by Directive 2001/20/EC of the European Parliament and of the Council of 4th April 2001. Prior to the entry into force of this Directive the rules for performing clinical trials varied significantly in the EU as they were based on differing regulatory approaches in the Member States. The Directive establishes specific provisions regarding the conduct of clinical trials including multi-centre trials on human subjects involving medicinal products (article $1 \S 1$ ). Article 3 of the Directive contains rules to protect clinical trial subjects in general, while article 4 regulates clinical trials on minors and article 5 clinical trials on incapacitated adults not able to give informed consent. The Directive does not address clinical trials in emergency situations. For the purposes of implementation of the Directive, article $6 \S 1$ obliges the Member States of the EU to take the measures necessary for the establishment and operation of ethics committees. Article 2 (k) defines an 'ethics committee' as follows: 'an independent body in a Member State, consisting of healthcare professionals and non-medical members, whose responsibility it is to protect the rights, safety and well-being of human subjects involved in a trial and to provide public assurance of that protection, by, among other things, expressing an opinion on the trial protocol, the suitability of the investigators and the adequacy of facilities, and on the methods and documents to be used to inform trial subjects and obtain their informed consent'. Before a clinical trial commences, the competent ethics committee

\footnotetext{
${ }^{1}$ Com (2008) 668 final.

${ }^{2}$ ENTR/F/2/SF D (2009) 32674.

${ }^{3}$ Com (2012) 369 final.
} 
has to give its opinion having regard in particular the topics mentioned in article $6 \S 3$. The ethics committee has to give its reasoned opinion within a maximum of 60 days from the date of receipt of a valid application to the applicant and the competent authority in the Member State concerned (article 6 §5). For multi-centre clinical trials ${ }^{4}$ limited to the territory of a single Member State, Member States have to establish a procedure providing for the adoption of a so called single opinion for that Member State, notwithstanding the number of ethics committees. In the case of multi-centre clinical trials carried out in more than one Member State simultaneously, a single opinion has to be given for each Member State concerned by the clinical trial (article 7). The sponsor of a clinical trial may not start a clinical trial until the ethics committee has issued a favourable opinion and inasmuch the competent authority of the Member State (National Competent Authority, further NCA) has not informed the sponsor of any grounds for non-acceptance of his valid request for authorization to conduct a clinical trial (article $9 \S 1$ ). This is called a tacit authorisation. The procedures to reach these decisions (the opinion of the ethics committee on the one hand and the decision on the acceptability of the trial by the competent authority of the Member State on the other) can be run in parallel or not, depending on the sponsor. Consideration of a valid request for authorisation by the competent authority has to be carried out as rapidly as possible and may not exceed 60 days (article 9 §4). The Directive contains a provision regarding the civil and criminal liability of the sponsor or the investigator of a clinical trial (article $19 \S 1$ ) and requires that provision has been made for insurance or indemnity to cover the liability of the investigator and sponsor [article $3 \S 2$ (f)].

\section{The Assessment of the Directive and Key Issues to be Addressed}

In its Communication of 10th December 2008 on 'Safe, innovative and accessible medicines: a renewed vision for the pharmaceutical sector' ${ }^{5}$ the European Commission announced that an assessment would be made of the clinical trials Directive. In October 2009, the Commission published a Public Consultation Paper regarding the envisaged assessment. ${ }^{6}$ The Consultation Paper raised

\footnotetext{
${ }^{4}$ Defined in article 2 (b) of the Directive as a clinical trial conducted according to a single protocol but at more than one site, and therefore by more than one investigator, in which the trial sites may be located in a single Member State, in a number of Member States and/or in Member States and third countries.

${ }^{5}$ COM (2008) 668 final.

${ }^{6}$ ENTR/F/2/SF D (2009) 32674.
}

different so called key issues. Those pertinent to this contribution are briefly discussed here.

Key issue no. 1 to be addressed according to the Consultation Paper concerned the 'multiple and divergent assessments of clinical trials' under the Directive. Each clinical trial is subject to an assessment by two distinct bodies, the NCA and the competent ethics committee(s) of each Member State concerned. As the scopes of the respective assessments are not coherently separated in the Community, it is difficult for NCAs of different Member States concerned to cooperate in the assessment procedure. This adds to the complication of the authorisation of clinical trials by NCAs in the Community. ${ }^{7}$ In order to roll out a clinical trial based on one protocol, in every Member State planned, the sponsor has to wait-apart from the approval by the ethics committee-for the (tacit) authorisation from the NCA of each of the Member States individually. This has led to a situation where the time-lag between the finalisation of the clinical trials protocol and the 'first patient in' becomes unnecessarily long. Since the entry into force of the Directive, this delay has increased by $90 \%$ and is now reaching in average $\sim 152$ days. $^{8}$ In order to address the issue as regards the assessment by NCAs the Consultation Paper submitted different options for consultation. One of these options envisages a communitywide streamlining of the NCA-authorisation process for clinical trials. According to this option, this authorisation process would be changed so as to ensure a strong cooperation of Member States. Regarding the assessment by ethics committees, the Consultation Paper stressed that ethical issues fall within the ambit of Member States and should remain there. Notwithstanding this, the Paper considered it worthwhile to evaluate how cooperation and exchange amongst national ethics committees, as well as procedural best practices, could be promoted in order to improve the ethical review of a clinical trial. One of the options proposed would introduce a so called 'one-stop shop' for the submission of the request for authorisation of a clinical trial to the NCAs and the ethics committee in order to reduce the administrative burden of multiple submission of information to separate actors, while maintaining the role of independent ethics review in accordance with international guidelines and principles. Another option was to revise the Directive to ensure that there is legal clarity of the respective scope of assessment by NCAs and ethics committees in the Member States.

Key issue no. 2 to be addressed regards the inconsistent implementation of the Directive. The Directive aims at an exhaustive harmonisation of the regulatory framework for

\footnotetext{
7 Idem, p. 12.

8 Idem, p. 13.

9 Idem, p. 17.
} 
clinical trials. However, it has achieved this aim only to a limited extent. This is due to the inconsistent application of the Directive. One of the options the Consultation Paper proposes to address this issue is to repeal the Directive and readopt its content in the form of a Regulation. Unlike a Directive, which only binds Member States as to the result to be achieved while leaving to them the choice of form and methods, ${ }^{10}$ a Regulation would remove national transposition measures, thereby ensuring that NCAs and ethics committees base their assessment on an identical text, rather than on diverging national transposition measures. Moreover, the legal form of a Regulation would make it possible to address the submission process for the request for authorisation in greater detail in a binding manner. ${ }^{11}$

Key issue no. 4 of the Consultation Paper concerns adaptation to peculiarities in trial participants and trial design. Clinical trials are performed in many different settings and with different groups of trial participants. This raises the question whether the various constellations are adequately addressed. One example relates to clinical trials in the paediatric population and another relates to clinical trials in emergency situations. As already mentioned before, this situation is not addressed in the rules for obtaining informed consent in the Directive. One of the options to address this issue is an adaptation of the Directive to introduce a regime which, on the one hand, ensures the safety and ethical soundness of clinical trials, while making it on the other hand possible to perform emergency trials where necessary. ${ }^{12}$

\section{The Proposed Regulation on Clinical Trials and Its Scope}

After the consultation procedure, the Commission published on 17th July 2012 a proposal for a Regulation of the European Parliament and of the Council on clinical trials on medicinal products for human use, and repealing Directive 2001/20/EC. ${ }^{13}$ As already mentioned in the Consultation Paper, the legal form of a Regulation should ensure a coherent procedure for submission of applications for authorisation of clinical trials. Experience had shown the difficulties that are created if Member States, in their cooperation, base their work on 'similar, but different' transposing national laws.

\footnotetext{
10 According to article $249 \S 3$ of the Treaty establishing the European Community.

${ }^{11}$ Consultation Paper, p. 20-21.

12 Idem, p. 26.

${ }^{13}$ Com (2012) 369 final.
}

Only the legal form of a Regulation ensures that the Member States base their assessment of an application for authorisation of a clinical trial on an identical text, rather than on diverging national transposition measures. It is not the aim of this contribution to describe the proposal for a Regulation in its entirety. It is limited on how the proposed Regulation regulates the assessment of clinical trials by ethics committees and the protection of participants in clinical trials compared with the existing rules in the Directive.

First, an important remark has to be made concerning the scope of the Regulation compared to the Directive. The Directive is applicable to clinical trials "carried out in either one site or multiple sites, whether in one or more than one Member State' [article 2 (a)]. It also contains a definition of 'multi-centre trial' [article 2 (b)]. The proposed Regulation does not contain analogous provisions in this regard. As already mentioned the proposal aims at ameliorating the cooperation of the NCAs when assessing a request for authorisation of a clinical trials. Without stating it explicitly, the proposal does not deal with mono-centric trials or even multi-centre trials in only one Member State as there is no need to cooperate among NCAs in that situation. From a European law point of view, it is logic that the proposal does not deal with a situation that only regards one Member State. In this respect, it is important to highlight that according to the Explanatory Memorandum of the proposed Regulation $\sim 24 \%$ of all clinical trials applied for in the EU are multinational clinical trials, i.e. clinical trials intended to be performed in at least two Member States. While this seems a relatively small proportion, these $24 \%$ clinical trials involve $\sim 67 \%$ of all subjects enrolled in a clinical trial. This means that, on average, a clinical trial with more than 40 subjects is conducted in more than one Member State. Mono-national clinical trials are limited to small studies with low recruitment targets. ${ }^{14}$

\section{The Ethical Assessment of Clinical Trials under the Proposed Regulation}

As mentioned already, the Directive contains a doubletrack authorisation procedure, one by the competent ethics committee(s) and another by the NCA. Both can be run in parallel or not, depending on the sponsor. The proposed Regulation provides for one overall authorisation procedure for a clinical trial in Chapter II. Each clinical trial falling in the scope of the proposed Regulation is subjected to authorisation in accordance with that Chapter (article 4). The ethical assessment of the clinical trial is part of the overall authorisation procedure and therefore we have to

\footnotetext{
${ }^{14}$ Explanatory Memorandum to the Proposal, p. 2.
} 
analyse the entire procedure without going too much into the technical details.

In order to obtain an authorisation, the sponsor has to submit an application dossier to the intended Member States concerned ${ }^{15}$ through the portal referred to in Article 77 (hereinafter 'EU portal'). He has also to propose one of these Member States as so called 'reporting Member State'. Where the proposed reporting Member State does not wish to be the reporting Member State, it has to agree with another Member State concerned that the latter will be the reporting Member State. If no Member State concerned accepts to be the reporting Member State, the proposed reporting Member State shall be the reporting Member State (article $5 \S 1$ ).

The reporting Member State has to make up an assessment report, consisting of two parts. Part I covers the aspects where Member States cooperate in the assessment for authorisation of a clinical trial (article 6) while Part II of the assessment report covers aspects of an intrinsic ethical or national/local nature where the assessment is made by each Member State concerned individually (article 7 of the proposed Regulation). The latter includes aspects such as liability, informed consent and suitability of the clinical trial site. ${ }^{16}$

\section{Assessment of Aspects Covered by Part I of the Assessment Report}

The assessment of the aspects falling under Part I of the assessment report is the responsibility of the reporting Member State (article $6 \S 1$ and §2). From a medical legal/ ethical point of view, the main aspects of this category are the anticipated therapeutic and public health benefits of the protocol and the risks and inconveniences for the subjects participating in the trial [article $6 \S 1$ (a) (i) and (ii)].

The reporting Member State has to submit Part I of the assessment report, including its conclusion, to the sponsor and to the other Member States concerned within the following time periods: (i) within 10 days from the validation date $^{17}$ for low-intervention clinical trials ${ }^{18}$; (ii) within

\footnotetext{
15 The 'Member State concerned' is defined in article 2 (11) as 'the Member State where an application for authorisation of a clinical trial or of a substantial modification has been submitted under Chapters II and III of this Regulation'.

16 Explanatory Memorandum to the Proposal, p. 4-5.

17 The 'validation date' of the application is the date on which the sponsor is notified by the reporting Member State that the clinical trial falls within the scope of the Regulation (article 5 \$5).

18 A 'low-intervention clinical trial' is defined in article 2 (3); one of the elements of this definition is that the additional diagnostic or monitoring procedures do not pose more than minimal additional risk or burden to the safety of the subjects compared to clinical practice in any Member State concerned. Compared to the Directive, this is a novel notion.
}

25 days from the validation date for clinical trials other than low-intervention clinical trials and (iii) within 30 days from the validation date for any clinical trial with an advanced therapy investigational medicinal product.

Until the assessment date ${ }^{19}$ any Member State concerned that is not the reporting Member State may communicate to the reporting Member State any considerations relevant to the application. The reporting Member State has to take those considerations duly into account (article 6 §5). The reporting Member State, and only the reporting Member State, may, between the validation date and the assessment date, request additional explanations from the sponsor, taking into account the considerations of non-reporting Member States (article 6 §6).

Part I of the assessment report has to contain one of the following conclusions: (a) the conduct of the clinical trial is acceptable in view of the requirements set out in the Regulation; (b) the conduct of the clinical trial is acceptable in view of the requirements set out in the Regulation, but subject to compliance with specific conditions which are specifically listed in that conclusion or (c) the conduct of the trial is not acceptable in view of the requirements set out in the Regulation.

\section{Assessment of Aspects Covered by Part II} of the Assessment Report (Ethical Assessment)

While the assessment of the aspects covered by Part I of the assessment report is the responsibility of the reporting Member State, each Member State concerned has to assess, for its own territory, the application with respect to the ethical aspects. They are eight in total and are enumerated in article 7 §1: (1) compliance with the requirements for informed consent as set out in Chapter $\mathrm{V}^{20}$; (2) compliance of the arrangements for rewarding or compensating investigators and subjects with the requirements set out in Chapter V; (3) compliance of the arrangements for recruitment of subjects with the requirements set out in Chapter V; (4) (d) compliance with Directive 95/46/EC on the protection of individuals with regard to the processing of personal data; (5) compliance with article 46 of the Regulation (suitability of individuals involved in conducting the clinical trial); (6) compliance with article 47 of the Regulation (suitability of trial sites); (7) compliance with article 72 of the Regulation (damage compensation and national indemnification mechanism) and (8) compliance with the applicable rules for the collection, storage and

\footnotetext{
19 The 'assessment date' is the date on which the assessment report is submitted to the sponsor and to the other Member States concerned (article 6 §).

${ }^{20}$ Chapter $\mathrm{V}$ of the proposed Regulation deals with the protection of subjects and informed consent. It is discussed in the next paragraph.
} 
future use of biological samples of the subject. The assessment of all these aspects constitutes Part II of the assessment report (article $7 \S 1$ ).

Each Member State concerned has to complete its assessment within 10 days from the validation date. This is very short period of time, especially when compared with the Directive that provides for a maximum of 60 days from the date of receipt of a valid application (article $6 \$ 5$ of the Directive). Each Member State concerned may request, with justified reasons, additional explanations from the sponsor only within that 10 days time period (article 7 \$2). For the purpose of obtaining additional explanations from the sponsor, the Member State concerned may suspend the period of 10 days for a maximum of another 10 days. Where the sponsor does not provide additional explanations within the time period set by the Member State the application is considered as withdrawn. However, this withdrawal applies only with respect to the Member State concerned (article $7 \S 3$ ).

Another striking difference between the Directive and the proposed Regulation concerns the competent body to assess the ethical aspects. As already mentioned the Directive contains an obligation for the Member States to establish ethics committees that have to give an opinion on the trial protocol (article 6 of the Directive). The proposal for a Regulation, however, does not even refer to the notion of ethics committee. Once the Directive is repealed there is no legal obligation anymore to establish ethics committees to assess clinical trials. But Member States can continue to rely upon (already existing or newly established) ethics committees for the assessment of the ethical aspects of a clinical trial. Indeed, the proposal for a Regulation leaves it to the Member State concerned to determine the appropriate body or bodies to be involved in this assessment. This decision is a matter of internal organisation of each Member State. ${ }^{21}$ But the Member States are not completely autonomous in determining this appropriate body as they have to respect articles 9 and 10 of the proposed Regulation. Article 9 contains the following rules. First, Member States have to ensure that the persons validating and assessing the application do not have conflicts of interest, are independent of the sponsor, the institution of the trial site and the investigators involved, as well as free of any other undue influence (article $9 \$ 1$ ). The notion of independency already appears in the definition of 'ethics committee' in article 2 (k) of the Directive. Secondly, Member States have to ensure that the assessment is done jointly by a reasonable number of persons who collectively have the necessary qualifications and experience (article 9 $\S 2)$. Finally, in the assessment, the view of at least one person whose primary area of interest is non-scientific has

${ }^{21}$ See 'Whereas' (14) of the Proposal. to be taken into account. The view of at least one patient has to be taken into account (article 9 §3). This requirement is stricter than the Directive which only states that an ethics committee has to consist of 'healthcare professionals and non-medical members' [article $2(\mathrm{k})$ of the Directive].

Article 10 imposes specific requirements for the ethical assessment when vulnerable persons participate in a clinical trial. Where the subjects are minors, specific consideration has to given to the assessment of the application for authorisation of a clinical trial on the basis of paediatric expertise or after taking advice on clinical, ethical and psychosocial problems in the field of paediatrics (article $10 \$ 1$ ). This is comparable with article 4 (h) of the Directive that requires that a clinical trial on minors has to be endorsed by an ethics committee 'with paediatric expertise of after taking advice in clinical, ethical and psychosocial problems in the field of paediatrics'. Where the subjects are incapacitated, specific consideration has to be given to the assessment of the application for authorisation of a clinical trial on the basis of expertise in the relevant disease and the patient population concerned or after taking advice on clinical, ethical and psychosocial questions in the field of the relevant disease and the patient population concerned (article $10 \S 2$ of the proposal). This in turn is comparable with article $5(\mathrm{~g})$ of the Directive that provides that inclusion in clinical trials of incapacitated adults is only allowed where an ethics committee, with expertise in the relevant disease and the patient population concerned or after taking advice on clinical, ethical and psychosocial questions in the field of the relevant disease and the patient population concerned has endorsed the protocol. In applications for authorisation of clinical trials referred to in article 32 (clinical trials in emergency situations) specific consideration has to be given to the circumstances of the conduct of the clinical trial (article 10 $\S 3)$. As the Directive does not regulate clinical trials in emergency situation, it is logic that it does not contain a comparable provision.

\section{Final Decision on the Clinical Trial}

Each Member State concerned has to notify the sponsor through the EU Portal as to whether the clinical trial is authorised, whether it is authorised subject to conditions, or whether authorisation is refused. This notification has to be done by way of one single decision within 10 days from the assessment date (article 8 \$1). When notifying their conclusion to the sponsor the Member States concerned have in principle to respect the conclusion of the reporting Member State as regards Part I of the assessment report. This is provided by article $8 \S 2$, sub $\$ 2$ of the proposed Regulation: 'Where the conclusion as regards Part I of the assessment report of the reporting Member State is that the 
conduct of the clinical trial is acceptable or acceptable subject to conditions, the conclusion of the Member State concerned shall be the same as that of the reporting Member State'. However, a Member State concerned may disagree with the conclusion of the reporting Member State on (only) two grounds. First, when significant differences in normal clinical practice ${ }^{22}$ between the Member State concerned and the reporting Member State would lead to a participant in the clinical trial receiving an inferior treatment than in normal clinical practice. In this case, the Member State concerned has to communicate its disagreement, together with a detailed justification based on scientific and socio-economic arguments, and a summary thereof, through the EU portal to the Commission, to all Member States, and to the sponsor. The second ground to disagree with the conclusion of the reporting Member State is infringement of the national legislation of the Member State concerned referred to in article $86 .^{23}$

Where the Member State concerned has not notified the sponsor of its decision within 10 days from the assessment date, the conclusion on Part I of the assessment report made up by the reporting Member State is considered as the decision of the Member State concerned on the application for authorisation of the clinical trial (article 8 §4) (so called tacit authorisation). Where, regarding Part I of the assessment report, the clinical trial is acceptable or acceptable subject to conditions, the Member State concerned has to include in its decision its conclusion on Part II of the assessment report (article 8 §4). In my opinion, the proposed Regulation remains vague regarding the consequences of a negative assessment of the 'ethical' aspects of a clinical trial in a Member State concerned. As already mentioned the proposed Regulation states that where the sponsor does not provide additional explanations regarding these local aspects within the time period set by the Member State the application is considered as withdrawn. This withdrawal only applies with respect to the Member State concerned (article 7 §3). But there is no provision in the proposed Regulation on the consequences of a negative assessment of the ethical aspects of a clinical trial in one of the Member States concerned. In order to respect the competence of each individual Member State to assess those aspects the only plausible consequence seems

\footnotetext{
22 According to article 2 (6) of the proposal for a Regulation, "normal clinical practice' is 'the treatment regime typically followed to treat, prevent or diagnose a disease or a disorder'.

${ }^{23}$ Article 86 of the proposal for a Regulation provides : 'This Regulation shall not affect the application of national legislation prohibiting or restricting the use of any specific type of human or animal cells, or the sale, supply or use of medicinal products containing, consisting of or derived from those cells, on grounds not dealt with in this Regulation. The Member States shall communicate the national legislation concerned to the Commission.'
}

to be that the application has to be considered as withdrawn with respect to the Member State concerned. The Regulation should provide this explicitly.

\section{The Protection of Subjects}

Article 3 of the proposed Regulation contains the general principle according to which a clinical trial may only be conducted if the rights, safety and well-being of subjects are protected and the data generated in the clinical trials are going to be reliable and robust. These rights are further elaborated in Chapter V of the proposed Regulation that deals with the protection of subjects and informed consent.

\section{General Rules}

Article 28 of the proposed Regulation contains 'general rules' for the protection of subjects in clinical trials. Article $28 \S 1$ provides that a clinical trial may be conducted only where the following conditions are met: the anticipated therapeutic and public health benefits justify the foreseeable risks and inconveniences; the subject or, where the subject is not able to give informed consent, his or her legal representative has given informed consent; the rights of the subject to physical and mental integrity, to privacy and to the protection of the data concerning him or her in accordance with Directive 95/46 are safeguarded. These requirements are comparable with the rules laid down in article $3 \$ 2$ (a), (b) and (c) of the Directive. ${ }^{24}$ Article $28 \S 2$ of the proposed Directive requires that the rights, safety and well-being of the subjects prevail over the interests of science and society. Under the Directive, this is not a general rule but a specific requirement for clinical trials on minors [article 4 (i)] and incapacitated adults [article $5(\mathrm{~h})$ ]. According to article $28 \S 3$ of the proposed Directive, any subject may, without any resulting detriment, withdraw from the clinical trial at any time by revoking his or her informed consent. The withdrawal of consent will not affect the activities carried out based on consent before its withdrawal. Article 3 \$2 (e) of the Directive also provides for the right to withdraw from the clinical trial at any moment but without adding the withdrawal of consent will not affect the activities already carries out before the withdrawal. This is a very useful clarification of the consequences of the withdrawal of consent.

A general rule to protect participants in the Directive that has not been incorporated in the proposal for a Regulation is contained in article $3 \$ 2$ (f) of the Directive. It requires that provision has been made for insurance or indemnity to cover the liability of the investigator and

\footnotetext{
${ }^{24}$ cf. Whereas (22): 'Directive 2001/20 contained an extensive set of rules for the protection of subjects. These rules should be upheld'.
} 
sponsor. However, the proposed Regulation deals with matters of indemnity and insurance in a separate Chapter (see below). Article $3 \S 3$ of the Directive provides that the medical care given to, and medical decisions made on behalf of subjects have to be the responsibility of an appropriately qualified doctor or, where appropriate, of a qualified dentist. Also this rule has not been integrated in the general rules of the proposed Regulation. Nonetheless article 46 of the proposed Regulation contains a comparable provision: 'The investigator shall be a medical doctor as defined in national law, or a person following a profession which is recognised in the Member State concerned as qualifying for an investigator because of the necessary scientific knowledge and experience in patient care. Other individuals involved in conducting a clinical trial shall be suitably qualified by education, training and experience to perform their tasks'.

\section{Informed Consent}

The requirement of informed consent as a general rule, is further spelled out in article 29 of the proposed Regulation. According to article $29 \S 1$ informed consent has to be written, dated and signed and given freely by the subject or his or her legal representative after having been duly informed of the nature, significance, implications and risks of the clinical trial. It has to be appropriately documented. Where the subject is unable to write, oral consent in the presence of at least one impartial witness may be given in exceptional cases. The subject or his or her legal representative has to be provided with a copy of the document by which informed consent has been given. Except for the last sentence, these requirements are also provided for in article $3 \S 2$ (d) of the Directive. Article $29 \S 2$ of the proposed Regulation requires that the written information given to the subject and/or the legal representative for the purposes of obtaining his or her informed consent has to be kept concise, clear, relevant and understandable to a lay person. It has to include both medical and legal information. It has to inform the subject about his or her right to revoke his or her informed consent. The requirement of information preceding consent is also contained in article 3 $\$ 2$ (b) of the Directive but the requirements in the proposal are more detailed and clear in different respects. Finally, article $29 \$ 3$ of the proposed Regulation states that the subject has to be provided with a contact point where he or she may obtain further information. This is comparable with article $3 \S 4$ of the Directive.

\section{Clinical Trials on Incapacitated Subjects}

Article 30 of the proposed Regulation contains additional rules for clinical trials on incapacitated subjects. Article 5 of the Directive deals with clinical trials on incapacitated adults. Given the definition ${ }^{25}$ of incapacitated subject in the proposed Regulation, this different terminology has no practical consequences. The contents of the protective measures is-with a few minor exceptions-exactly the same. The result is that incapacitated subjects may only participate in clinical trials with a direct benefit for them (also called therapeutic clinical trial) and that so called non-therapeutic trials remain unlawful once the Regulation has repealed the Directive. ${ }^{26}$

\section{Clinical Trials on Minors}

Article 31 of the proposed Regulation provides for additional rules for trials on minors. ${ }^{27}$ The rules in article $31 \S 1$ are the same as the rules contained in article 4 of the Directive with some minor changes. ${ }^{28}$ For instance, the rule contained in article 4 (e) of the Directive has been split up into three different rules in article $31 \S 1$ (e), (f) and (g) of the proposed Regulation. Also the wording is sometimes different. Article $31 \S 2$ provides that the minor takes part in the consent procedure. Such a rule is not provided for in the Directive. Like under the Directive, the criteria for the protection of incapacitated (adult) subjects are stricter than those concerning minors. ${ }^{29}$ Some criteria in the Directive have received criticism. For instance, article 4 (e) of the Directive requires that 'some direct benefit for the group of patients is obtained from the clinical trial'. It is not clear how this requirement of a 'group benefit' must be interpreted. Especially the expression 'group of patients' is tangling, as it does not necessarily restrict research to patients who are at the same time patients. In the light of the Explanatory Memorandum of the Directive, the notion 'group of patients' can be interpreted as the group of minors in general. In addition, also the specification of a 'group benefit' as a 'direct benefit' is confusing, as the

\footnotetext{
25 'Incapacitated subject': is a subject who is, for other reasons than the age of legal competence to give informed consent, legally incapable of giving informed consent according to the laws of the Member State concerned [article 2 (17)].

26 cf. T.K. Hervey and J.V. McHale, Health law and the European Union, Cambridge University Press, Cambridge, 2004, 254, commenting on the proposed Directive: 'The final drafting seems to suggest that non-therapeutic trials on medicinal products, concerning incompetent adults, will be unlawful when the Directive comes into force'.

27 'Minor': is a subject who is, according to the laws of the Member State concerned, under the age of legal competence to give informed consent [article 2 (16)].

${ }^{28}$ See for a discussion of article 4 of the Directive; Pinxten W, Dierickx K, Nys H (2011) Diversified harmony: supranational and domestic regulation of paediatric clinical trials in the EU. J Cystic Fibrosis 10 (suppl. 2):S183-S198.

${ }^{29}$ See Gevers JK (2008) Editorial. Medical research involving children. Eur J Health Law 15:103-108.
} 
'direct' character of a benefit implies that the beneficiary is the participating individual. ${ }^{30}$ Article $31 \S 1$ (h) of the proposed Regulation also provides that 'some direct benefit for the group of patients is obtained from the clinical trial'. In this respect, it is exposed to the same critical remarks.

\section{Clinical Trials in Emergency Situations}

Article 32 of the proposed Regulation is one of the most innovative provisions compared to the Directive as it contains rules on clinical trials in emergency situations. The Directive does not contain such rules and this has created much confusion among Member States. Since the entry into force of the Directive there has been a debate in the EU about whether the Clinical Trials Directive was de facto aiming at a ban on clinical trials for medicinal products used in the context of an emergency situation, as it is usually not possible to obtain informed consent from the patient or the legal representative for practical reasons. Some ten Member States ${ }^{31}$ have legislation in place allowing clinical trials in emergency situations. Other Member States have administrative guidelines on how to deal with these trials, in order to ensure that they can be performed. $^{32}$ In still other Member States where the Directive is read strictly no clinical trials in emergency settings have been approved since it entered into force. ${ }^{33}$ According to the Consultation Paper there is general agreement that, in principle, clinical trials of this kind are necessary in order to ensure a high level of human health, which is a fundamental policy aim of the Community [Article 152(2) EC Treaty]. The need for clinical trials in emergency situations is also reflected in various international guidelines, such as in the World Medical Association's Declaration of Helsinki on Ethical Principles for Medical Research Involving Human Subjects (as amended in 2008) and the Guidelines on good clinical practice of the International Conference on Harmonisation of Technical Requirements for Registration of Pharmaceuticals for Human Use (ICH E6). Indeed, it would be a very serious setback for clinical research if medicinal research in emergency situations proved to be impossible in Europe. ${ }^{34}$

Article $32 \S 1$ of the proposed Regulation provides for a derogation from the rule that the subject or, where the

\footnotetext{
$\overline{30}$ Pinxten W, Dierickx K, Nys H (2008) The implementation of Directive 2001/20/EC into Belgian law and the specific provisions on paediatric research. Eur J Health Law 15:155-156.

31 Among which Belgium.

32 Consultation Paper, p. 25.

33 e.g. Finland; see Halila R: Response to the Consultation Paper; available at http://ec.europa.eu/health/files/clinicaltrials/ctresp_201106/halila,_ritva.pdf.

${ }^{34}$ Consultation Paper, p. 25.
}

subject is not able to give informed consent, his or her legal representative has given informed consent. In this case informed consent may be obtained after the start of the clinical trial (so called deferred consent) to continue the clinical trial and information on the clinical trial may be given after the start of the clinical trial provided that all of the following conditions are fulfilled: (a) due to the urgency of the situation, caused by a sudden life-threatening or other sudden serious medical condition, it is impossible to obtain prior informed consent from the subject and it is impossible to supply prior information to the subject; (b) no legal representative is available; (c) the subject has not previously expressed objections known to the investigator; (d) the research relates directly to a medical condition which causes the impossibility to obtain prior informed consent and to supply prior information; (e) the clinical trial poses a minimal risk to, and imposes a minimal burden on, the subject.

According to article $32 \S 2$ the informed consent referred to in article $32 \S 1$ has to be obtained, and information on the clinical trial has to given, in accordance with the following requirements: (a) regarding incapacitated subjects and minors, the informed consent has to be obtained as soon as; possible from the legal representative and the information has to be given as soon as possible to the subject; (b) regarding other subjects, the informed consent has to obtained as soon as possible from the legal representative or the subject, whichever is sooner and the information has to be given as soon as possible to the legal representative or the subject, whichever is sooner. Where informed consent has been obtained from the legal representative, informed consent to continue the trial has to be obtained from the subject as soon as he is capable of giving informed consent.

\section{Damage Compensation, Insurance and National Indemnification Mechanism}

Directive 2001/20/EC introduced an 'obligatory insurance/ indemnity' [article $3 \S 2$ (f)]. According to the Explanatory Memorandum of the proposed Regulation this obligatory insurance/indemnity has substantially increased the costs and administrative burden of conducting clinical trials, but there is no evidence that the number of damages, or the amount, has increased with the entry into force of the Directive. ${ }^{35}$ The proposed Regulation acknowledges that clinical trials do not in all cases pose an additional risk to subjects compared to treatment in normal clinical practice. In these cases, the insurance coverage of the medical practitioner, the institution, or product liability insurance provides sufficient coverage. Article 72 of the proposed

\footnotetext{
${ }^{35}$ Explanatory Memorandum, p. 9.
} 
Regulation requires that for clinical trials other than lowintervention clinical trials, the sponsor has to ensure that compensation in accordance with the applicable laws on liability of the sponsor and the investigator is provided for any damage suffered by the subject. This damage compensation has to be provided independently of the financial capacity of the sponsor and the investigator.

Article $73 \S 1$ of the proposed Regulation obliges Member States to provide for a national indemnification mechanism for compensating damage as referred to in article 72. Experience has shown that the insurance market is small and costs for insurance coverage are disproportionately high. Moreover, as liability regimes differ widely between Member States, it is difficult and burdensome for the sponsor of a multinational trial to obtain insurance in accordance with those national laws. Therefore, Member States have to establish a national indemnification mechanism. ${ }^{36}$ According to article $73 \S 2$, the sponsor is deemed to comply with the obligation to ensure compensation provided for in article 72 where he makes use of the national indemnification mechanism in the Member State concerned. The use of this national indemnification mechanism is free of charge where, for objective reasons, the clinical trial was not intended, at the time of submission of the application for authorisation of that clinical trial, to be used for obtaining a marketing authorisation for a medicinal product. For all other clinical trials, the use of the national indemnification mechanism may be subject to a fee. Member States have to establish that fee on a not-forprofit basis, taking into account the risk of the clinical trial, the potential damage, and the likelihood of the damage (article $73 \S 3$ ). This will help in particular 'non commercial sponsors' to obtain coverage for possible compensations. These sponsors have had, since the introduction of the 'obligatory insurance/indemnity' with the Directive great difficulties to obtain compensation coverage. ${ }^{37}$

\section{Discussion}

The clinical trials Directive has had a major impact on the regulatory framework of clinical trials in the Member States of the EU and especially upon the protection of the rights of subjects participating in these trials. ${ }^{38}$ The obligation to implement the Directive into national law has been to many Member States (among which Belgium) a decisive trigger to adopt a protective regime for those subjects. In this respect, the merits of the Directive cannot be overestimated. However, as demonstrated by the

\footnotetext{
${ }^{36}$ See 'Whereas' (47) of the proposed Regulation.

37 Explanatory Memorandum, p. 10.

${ }^{38}$ Consultation Paper, p. 10.
}

Commission in the Consultation Paper, the Directive has also had some negative consequences on clinical trials in Europe. This has resulted in the Commission proposing a Regulation of the European Parliament and of the Council on clinical trials on medicinal products for human use, and repealing Directive 2001/20/EC. According to the Commission only the legal form of a Regulation will ensure that the Member States base their assessment of an application for authorisation of a clinical trial on an identical text, rather than on diverging national transposition measures. This decision is the result of a balancing of all interests at stake and is not a matter of discussion here. It is striking that also this year the Commission has made a proposal to replace the Directive 95/46/EC on the protection of individuals with regard to the processing of personal data by a Regulation. $^{39}$

One of the main conclusions - if not the most important one from a medical legal/ethical perspective-is that the proposed Regulation will not touch upon the substantial protective rights of subjects participating in clinical trials, at least not in a direct way. Although there are changes as to the formulation and presentation of some requirements their contents has remained basically unchanged. An important innovation are the rules on clinical trials in emergency situations. Although to some of these rules may be unacceptable because they do not respect (at least in the initial stage of a trial) the requirement of informed consent they may be welcomed because they bring the European legal framework in line with the Declaration of Helsinki. Moreover, different Member States of the EU have already provided for comparable rules in their national law without having been criticised of violating the clinical trials Directive. The proposed Regulation will reinforce the protection of minor participants by explicitly providing that the minor takes part in the consent procedure. On the other hand, it can be deplored that the Regulation has not taken serious enough the critics regarding the requirement that 'some direct benefit for the group of patients is obtained from the clinical trial' in which minors participate. This requirement can be interpreted in different ways and even a Regulation will not guarantee the expected harmonisation. An important amelioration is that the proposed Regulation contains much more detailed provisions to guarantee damage compensation to subjects than the Directive although some may regret that no specific insurance/compensation mechanism is required anymore for lowintervention clinical trials, a novel notion.

\footnotetext{
39 See http://ec.europa.eu/justice/data-protection/document/review 2012/com_2012_11_en.pdf. See also Opinion No. 26 on Ethics of Information and Communication Technologies of the European Group on Ethics of Science and New Technologies to the European Commission of 22th February 2012.
} 
The assessment of the requirements to guarantee the protection of subjects and of other ethical aspects of a clinical trial will undergo important changes. Some of them are ameliorations compared to the Directive. The proposed Regulation contains stricter requirements regarding the composition of the body responsible for the ethical assessment to ensure that its members do not have conflicts of interest, are independent of the sponsor, the institution of the trial site and the investigators involved, as well as free of any other undue influence. The assessment has to be done jointly by a reasonable number of persons who collectively have the necessary qualifications and experience and in the assessment the view of at least one person whose primary area of interest is non-scientific and of at least one patient has to be taken into account. Not few probably will deplore that the very notion of 'ethics committee' will disappear out of the European legal framework for clinical trials. One may wonder what the motives are to neglect this worldwide accepted notion of research ethics. But its consequences should probably not be exaggerated neither. Indeed, the proposed Regulation leaves it to the Member States to determine the appropriate body or bodies to be involved in the ethical assessment and one may expect that most Member States, if not all, will continue to rely upon (already existing or newly established) ethics committees for the assessment of the ethical aspects of a clinical trial. In this regard, it is important to recall that the scope of the proposed Regulation is less wide than the Directive. Only multi-centre trials in at least two Member States are addressed by the proposed Regulation. As a consequence existing national rules regarding ethics committees to assess mono-centric trials or national multi-centric trials remain out of the scope of the proposed Regulation and can be maintained.

The proposed Regulation is very disappointing-especially for all those who engaged themselves in one of the 1.900 ethics committees involved in the assessment of clinical trials in Europe ${ }^{40}$ — with regard to the time allotted to the bodies that I will continue to call 'ethics committees' to assess the ethical aspects of a trial, namely 10 days from the validation date. Even if these are working days-the proposed Regulation does not make it clear-it remains a much too short period of time irrespective of whether the trial in a low-intervention trial or another than a lowintervention trial to assess the compliance with the eight requirements enumerated in article 7 \$1. At least the impression has been created that the ethics committees are to be blamed for the longer delays for starting a clinical trial in Europe since the Directive entered into force. This is the more deplorable because there is nothing in the Consultation Paper to justify such a negative evaluation. On the contrary, the Paper suggested it to be "worthwhile considering how cooperation and exchange amongst national ethics committees, as well as procedural best practices, could be promoted in order to improve the ethical review of a clinical trial'. ${ }^{41}$ Such cooperation and exchange is of course impossible in the short notice provided for by the proposed Regulation. The European Parliament-that was very successful in amending the proposal for the Directive on clinical trials to guarantee the substantial protection of participants-and the Council have to use any justified means to amend the proposed Regulation in this regard. This is not just a matter of detail but touches upon the very core of any regulatory framework for medical research: reliable guarantees for protection and trust of participants.

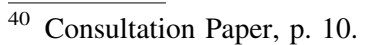

$\overline{41}$ Consultation Paper, p. 17. 